\title{
Thermal Modeling of Upward Wall Flame Spread
}

\author{
YUJI HASEMI \\ Building Research Institute \\ Ministry of Construction \\ Tatehara 1, Oho-machi, Tsukuba-gun \\ Ibaraki-ken, 305, Japan
}

\section{ABSTRACT}

This paper describes an engineering model of the upward turbulent flame spread along a vertical combustible surface based on a concept of ignition and flame spread as a result of inert heating of the solid to an ignition temperature. Experiments were made by using porous line burners to represent the wall flame heat transfer as a function of heat release rate and pyrolysis length. An exploratory analysis was made to correlate flame spread properties with thermometric material properties based on this model. This analysis seems to be consistent with current experimental work on turbulent wall flames.

\section{INTRODUCTION}

Control of the combustibility of wall is evidently essential to prevent a rapid fire growth in an enclosure, since fires tend to develop much faster along a wall than on a floor. Although most conventional theoretical work on flame spread has assumed an ideal laminar flame without radiation(1-3), a wall flame during a building fire is usually turbulent, and its spread is dominated by flame radiation $(4,5)$. While the turbulent flame spread may result from complicated interactions of chemical, kinetic and thermal processes(6), an engineering model of steady turbulent wall flame spread was formulated on the basis of a concept of ignition and flame spread as a result of inert heating of the solid to an ignition temperature $(7,8)$; Figure 1 shows its conception. This model assumes a one-dimensional flame spread in the $x$-direction and a one-dimensional thermal conduction in the solid normal to the surface. The location of the pyrolysis front is identified by $x$ where the surface temperature has reached an ignition temperature, $T$. The aim of this paper is to formulate the flame spread velocity as a function of known material properties and correlate relevant thermal processes with material properties by experiments.

\section{FORMULATION OF WALL ELAME SPREAD}

If the formation of char at the fuel surface is negligible or ignored, the surface temperature at $x, T_{w}(x, 0)$, can be represented by the convolution as

$T_{W}(x, 0)-T_{0}=\int_{0}^{t_{W}^{\prime \prime}}(x, t-\tau) \cdot \phi(\tau) d \tau$

where $\check{q}_{W}^{\prime \prime}(x, t-\tau)$ is the heat $f l u x$ applied to the surface at ( $\left.t-\tau\right)$ after the 


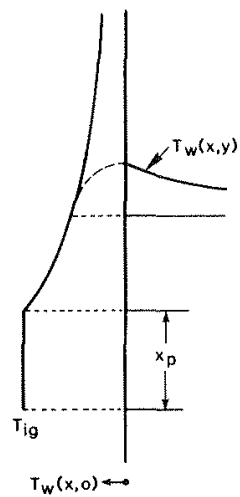

Wall temperature

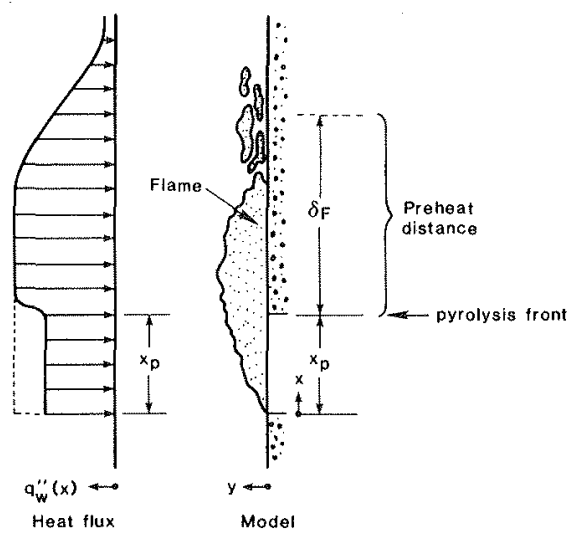

FIGURE 1. Schematic diagram of upward flame spread.

ignition. $\phi(\tau)$ is an impulse response of the surface temperature to heat application, and its functional. form is dependent on wall conditions. The location of the pyrolysis front is given as a function of time by solving

$$
T_{i g}-T_{0}=\int_{0}^{t} \dot{q}_{W}^{n}(x, t-\tau) \cdot \phi(\tau) d \tau
$$

for $x$. This equation can be solved for $x$ only implicitly; however, it may be transformed into an explicit form for $x$ by assuming some dependence of the location of pyrolysis front on time; most analysis on flame spread has dealt with a steady flame spread, i.e. $\nabla_{m}=\mathrm{dx} / \mathrm{d} t=$ constant. Similar situation will be studied in this paper for the followilg two simple wall conditions. The limit of equation (2) as $t \rightarrow \infty$ should be considered for this analysis, since the steady flame spread velocity must not depend on time.

\section{Semi-infinite Thick Combustible Wa11}

Ignoring the surface reradiation just for the simplifity, the impulse response function, $\phi(\tau)$, can be represented as $\phi(\tau)=(\pi k \rho c \tau)^{-1 / 2}$. Assuming i is independent of $f$ lame spread velocity and replacing $\tau$ with $x_{p}$ by $x_{p}=-V_{p} \tau$, then
equation (2) will become

$$
T_{i g}-T_{0}=\int_{-\infty}^{x} \frac{\dot{q}_{w}^{\prime \prime}\left(x-x_{p}+L_{p}\right)}{\sqrt{\pi k_{\rho} c V_{p}\left(x-x_{p}\right)}} d x_{p}
$$

Equation (3) can be solved for $\mathrm{V}_{\mathrm{p}}$ as

$$
\mathrm{v}_{\mathrm{p}}=\left\{\int_{0}^{\infty} \dot{\mathrm{q}}_{\mathrm{w}}^{\prime \prime}\left(\xi+\mathrm{I}_{\mathrm{p}}\right) / \sqrt{\xi} d \xi\right\}^{2} / \pi k \rho c\left(\mathrm{~T}_{i \mathrm{~g}}-\mathrm{T}_{\mathrm{o}}\right)^{2}
$$

where $\xi$ is the height above the pyrolysis front. This equation yields the Sibulkin-Kim relationship of wall flame spread(7), if the surface heat flux is represented as $\dot{q}_{W}^{\prime \prime}=q_{0}^{\prime \prime} \cdot \exp (-\xi / \sigma)$ with constant $\dot{q}_{0}^{\prime \prime}$ and $\sigma$. 


\section{Thermally Thin Wall With Newtonian Cooling}

For a thin wall whose temperature is regarded as uniform in the normal direction to its surface(Figure 2), the impulse response function, $\phi(t)$, can be represented as $\phi(t)=\exp \left(-h_{i} t / \rho c d\right)$ where $h_{i}$ is the heat transfer coefficient. Substituting this into equation (2), the steady state flame spread velocity can be represented as

$$
v_{p}=\frac{1}{\rho c d\left(T_{i g}-T_{0}\right)} \cdot \int_{0}^{\infty} \dot{q}_{w}^{\prime \prime}\left(\xi+L_{p}\right) \cdot \exp \left(-h_{i} \xi / \rho \operatorname{cdv} v_{p}\right) d \xi
$$

Iteration is necessary to solve equation (5) for $V_{p}$. However, for an insulated wall,i.e. $h_{i}=0$, equation (5) yields

$$
\mathrm{v}_{\mathrm{p}}=\frac{1}{\rho \mathrm{cd}\left(\mathrm{T}_{i g^{-T_{o}}}\right)} \cdot \int_{0}^{\infty} \dot{\mathrm{q}}_{\mathrm{w}}^{\prime \prime}\left(\xi+\mathrm{L}_{\mathrm{p}}\right) \mathrm{d} \xi
$$

In equations (4) and (6), such parameters as $\rho, c, k$ and $T_{i g}$ are the material properties to be determined by thermometric measurements. The integrals appearing in these equations can be estimated by formulating the distribution of $\dot{\mathrm{q}}_{\mathrm{w}}^{\prime \prime}$ as a function of height above pyrolysis front.

The wall heat flux in the flame is believed to be governed by flame radiation(4); this suggests that flame height can be a scaling factor representing the distribution of wall flame heat transfer. On the analogy of unconfined fires, the flame height is expected to depend practically only on gross heat release rate per unit length of the pyrolysis zone, $Q_{\ell}$, and pyrolysis length, L (e.g.10). Heat release rate is proportional to volatilization rate, ${ }^{\prime \prime}{ }^{\prime \prime}$, which ${ }^{\mathrm{i}}$, to be determined by the heat balance around the fuel surface as

$$
\dot{q}_{W}^{\prime \prime}-\dot{q}_{r r}^{\prime \prime}=\Delta \mathrm{H}_{G} \cdot \dot{\mathrm{m}}_{\mathrm{V}}^{\prime \prime}
$$

The surface reradiation, $\dot{q}_{r r}^{\prime \prime}$, is related to the temperature of fuel surface, $T_{i f}$, and its emissivity. Although the material properties appearing in this model ma not be obtained directly for some composite materials, the model will still serve as a paradigm to develop a testing method concerning the wall flame spread. Therefore, heat release rate can be again correlated with heat application to the fuel surface and such material properties as $\mathrm{I}_{\text {ig }}$ and calorific potential.

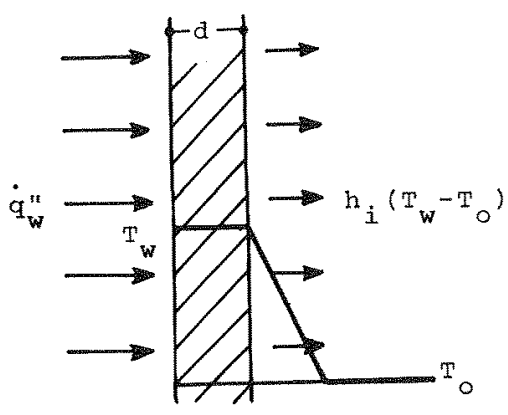

FIGURE 2. Thermally thin wall model. 
The central problem in estimating the flame spread properties from the present model is to formulate the distribution of wall flame heat transfer as a function of material properties. Since the intermittency of the flame is believed to dominate wa11 flame heat transfer due to radiation, flame height, either for flame tips and for solid flame, is expected to be a measure to represent the preheat distance of a burning wall. Thus, measurements of total heat flux to the wall surface and the visible flame height were made by using porous, methane, line burners against isothermal and thermally thin walls. Application of these burners were just for convenience; the behavior of flame near the burners may be different from that of vertical fuel. This difference will be discussed by comparing the present result with previous measurement on vertical wicks.

The isothermal wall had a smooth black-painted front surface, and it was water-cooled through coils on its back surface. Flat water-cooled side panels helped to maintain a two-dimensional flow pattern along the test wal1. The surfaces of the test wall and the side walls were kept at a constant temperature, approximate $1 \mathrm{y}, 60^{\circ} \mathrm{C}$. The widths of the methane burners were $0.0375 \mathrm{~m}$ and $0.082 \mathrm{~m}$. The thin-wa11 experiments were made by using a porous methane burner $0.075 \mathrm{~m}$ wide and $0.92 \mathrm{~m}$ in length against one wall of a $2.80 \mathrm{~m} \times 2.80 \mathrm{~m} \times 2.18 \mathrm{~m}$ enclosure covered with a ceramic fiber insulation board. A precise description of the enclosure is given elsewhere(11).

Total heat flux was monitored by Gardon-type flux meters. The reported values of total heat flux are the average of data recorded for 5 minutes at the intervals of 10 seconds. Heat release rate was estimated from the flow rate of the fuel gas, assuming complete combustion. visible flame was monitored by a video camera during both experiments. The reported values of flame height are the average of the height of flame tips observed for 3 minutes at intervals of 0.5 seconds on the videotape by three observers. The height of solid flame seemed to be less consistent among the observers.

\section{Flame Height Correlations}

For unconfined turbulent diffusion flames, dimensional analysis based on the Froude number has established a dependence of the flame height on the size and intensity of fuel(10); $Q=Q / \rho_{\infty} c_{p} T_{0} g^{1 / 2} p^{5 / 2}$ may be a dominant dimensionless parameter concerning this problem $\left(\frac{1}{3} 2\right)$. Similar analysis on a line fire results in a dependence of $f 1$ ame height on $Q_{\ell} \equiv Q_{q} / \rho_{\infty} C_{p} T_{o} g^{1 / 2} D^{3 / 2}$, since the square root of the inertial force to buoyancy ratio for a constant maximum temperature at each height, $\theta_{\mathrm{m}}$, can be represented as

$$
\left.\left(\mathrm{T}_{\mathrm{o}} / \mathrm{Dg} \theta_{\mathrm{m}}\right)^{1 / 2} \cdot \mathrm{u}_{\mathrm{c}}=\left(\mathrm{T}_{\mathrm{o}} / \mathrm{Dg} \theta_{\mathrm{m}}\right)^{1 / 2} \cdot Q_{\ell} / \rho_{\infty} \mathrm{C}_{\mathrm{p}} \theta_{\mathrm{m}} \mathrm{D} \propto Q_{\ell} / \rho_{\infty} \mathrm{C}_{\mathrm{p}} \mathrm{T}_{\mathrm{o}}(\mathrm{gD})^{3}\right)^{1 / 2}
$$

where the characteristic velocity, $u_{c}$, is defined as $u_{c} \equiv Q_{\ell} / \rho_{\infty} C_{p} \theta_{m} D$. Assuming the following functional expression for the flame height,

$$
L_{F}=\gamma \cdot Q_{\ell}^{*} \cdot D
$$

the power of $Q_{\ell}^{*}$ representing $L_{F}, n$, should approach $2 / 3$ for a large value of $Q_{\ell}^{*}$, since the fuel size effect on flame height must vanish in the $Q_{\ell \rightarrow \infty}^{*}$ limit. The parameter, $\gamma$, will take a particular value according to the definition of flame height. 


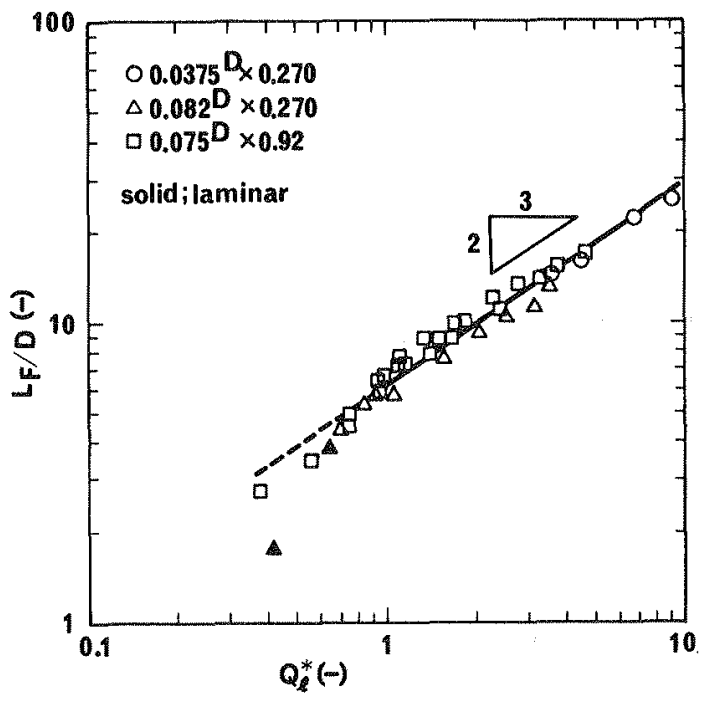

FIGURE 3. Height of flame tips vs. $Q_{\ell}^{*}$.

Figure 3 displays the dependence of $L_{F} / D$ on $Q_{\ell}^{*}$ based on the height of flame tips obtained from the three burners; the result shows that the height of wall flame is apparently proportional to $2 / 3$ power of $Q_{\ell}$ for $Q_{Q}>1$. The power of $Q_{k}^{*}$ representing the flame height appears to be slightly larger for $Q_{Q}<1$ than for $Q_{Q}$ $>1$, i. e. $n \approx 0.8$. The parameter, $\gamma$, is approximately 6.0 . This result seems to be very close to a recent anglysis by Delichatsios(13). The height of solid flame was approximate $1 \mathrm{y} \mathrm{L}_{\mathrm{F}} \simeq 2.8 \mathrm{Q}_{2}^{\mathrm{n}} \cdot \mathrm{D}$.

Heat Flux To The Wa11 Surface

A parameter $/ 2$ characterizing the visible flame height for a wide range, $Q_{Q}^{* 2 / 3}$ $D=\left(Q_{\ell} / \rho_{\infty} C_{T} g^{I / 2}\right)^{2 / 3}$, may be a characteristic scale length to classify the regions of an upward flow for the analysis of wall flame heat transfer. Figure 4 repyesents total heat flux to the isothermal wall against height normalized with $Q_{\ell}{ }^{2} \mathrm{D}$. The data of total heat $f 1 \mathrm{ux}$ for a $\mathrm{CO}$ burner and for a saturated vertical wicks obtained by Faeth et a1 $(9,14)$ are superimposed for reference. The arrows for the data of Liburdy and Faeth show the direction in which their data must move, because they used local heat flux estimated from temperature and velocity measurements instead of the heat release rate. The ratio of the local heat flux to the heat release rate, $Q_{x} / Q_{\ell}$, for the data of Liburdy and Faeth is estimated to be as low as 0.74 ; the length of each arrow shows the range of the correction.

The results of the five experiments are almost identical and they appear to cluster densely along one curve. For the analysis of the mechanism on wall flame heat transfer it may be convenient to classify the wall surface into the followigg three distinct regions.

I) $x / Q_{2} \mathrm{D}_{\leq} \leq 2,8$. solid flame):

For $\mathrm{x} / \mathrm{Q}_{\ell}^{2 / 3} \cdot \mathrm{D} \leqslant \mathrm{I}$, $\dot{\mathrm{q}}_{\mathrm{H}}^{\mathrm{i}}$ increased with height for $0.0375 \mathrm{~m}$ wide burner, while it was almost constant for $0.082 \mathrm{~m}$ wide one. For $\mathrm{x} / \mathrm{Q}_{\ell}^{* 2 / 3}, \mathrm{D}>1$, $\dot{\mathrm{q}}^{\prime \prime}$ is apparently constant with height, and it appears to be a weakly increasing function of $Q_{\ell}$ (Figure 5). 


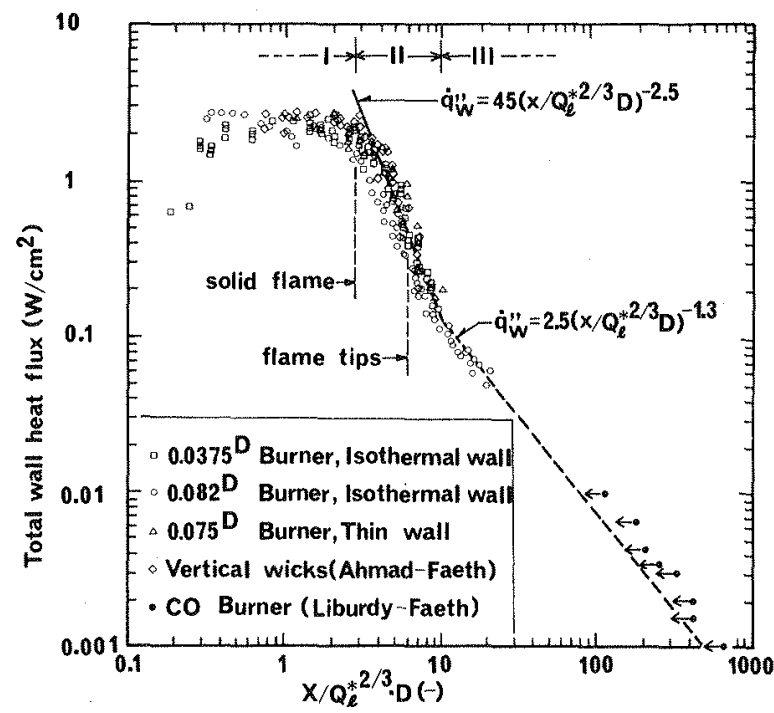

FLGURE 4. Total wall heat flux vs. normalized height.

II) $2.8 \leq x / Q_{\ell}^{* 2 / 3} \mathrm{D} \lesssim 10$ (transition region):

The slope is the steepest among the three regions; all data fall on the curve represented as

$\dot{\mathrm{q}}_{W}^{\prime \prime}=45\left(\mathrm{x} / \mathrm{Q}_{\ell}^{2 / 3} \cdot \mathrm{D}\right)^{-2.5}$

This region may be characterized by the intermittency of flame. Recent wall flame radiation measurement by Kulkarni(14) using the same apparatus shows that the radiative heat flux to a wall surface decreases significantly in this region.

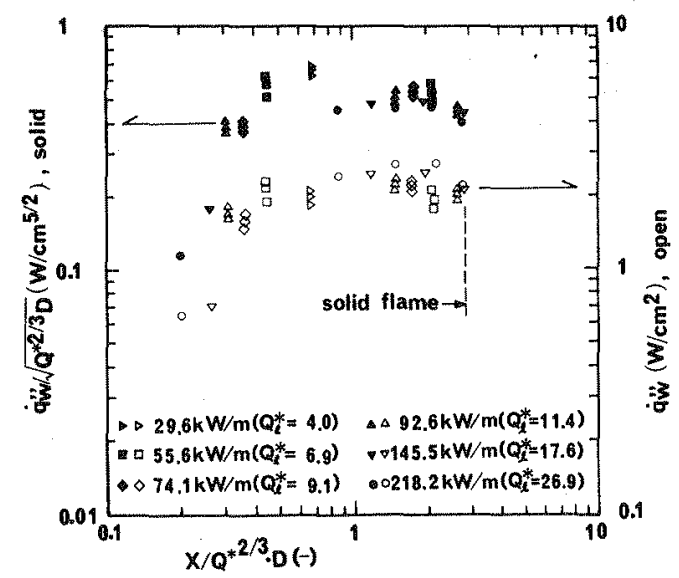

FIGURE 5. $\dot{q}_{w}^{\prime \prime}$ (open) and $\dot{q}_{\mathrm{w}}^{\prime \prime} / \sqrt{Q_{\ell}^{* 2 / 3} \mathrm{D}}$ (solid) vs. normalized height, $\left(0.0375 \mathrm{~m}^{\mathrm{D}}\right.$
burner). 
III) $x / Q^{* 2 / 3} \mathrm{D} \geq 10$ (plume region):

Although sufficient number of data have not been obtained for this region, the slope representing the dependence of heat flux on height is clearly less steep than in the transition region. Since the data of Liburdy and Faeth in Figure 4 must move slightly to the left in the figure, heat flux in this region will be represented approximately by

$\dot{q}_{w}^{\prime \prime}=2.5\left(x / Q_{\ell}^{* / 3} \cdot D\right)^{-1.3}$

\section{DEPENDENCE OF FLAME HETGHT AND FLAME SPREAD VELOCTTY ON PYROLYSIS LENGTH}

The present analysis has resulted in a goof correlation between incident wall heat flux and the normalized height, $\mathrm{x} / \mathrm{Q}_{\ell} / \mathrm{D}$; however, heat transfer within the pyrolysis zone should be still studied so that heat release rate can be represented as a function of material properties. For the heat transfer on a combusting surface, orloff et al(5) measured radiative flux using a $3.56 \mathrm{~m}$ high PMMA vertical slab and estimated convective heat flux; their measurement resulted in a proportionality of heat flux to $x^{0.2}$ for $x<1.0 \mathrm{~m}$ and to $x^{0.5}$ for $x>1$.0m. This proportionality is consistent with smooth wall heat transfer analysis for $\mathrm{x}<1 \mathrm{~m}$ and with rough wall analysis for $x>1 \mathrm{~m}(16)$. This seems to be the only measurement of the distribution of incident flux within the pyrolysis zone of a wall fire. An exploratory analysis was made to correlate such flame spread properties as flame height and flame spreading velocity with material properties on the basis of the present model and Orloff et al's experiment.

\section{Flame Height}

By combining equations(7) and (9), flame height can be represented as a function of incident heat flux at vaporizing surface as

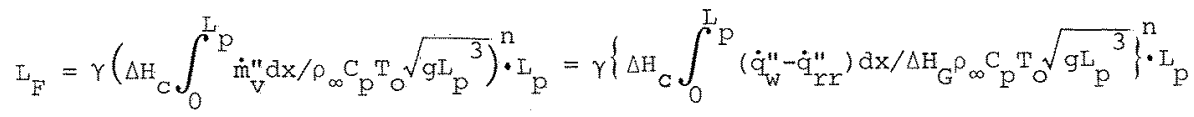

where $\Delta \mathrm{H}$ is the heat of combustion $(\mathrm{J} / \mathrm{g})$ and $\Delta \mathrm{H}_{\mathrm{G}}$ is the vaporization heat. Assuming $q^{\prime \prime}$ is proportional to $x^{0.2}$ for $x<1 \mathrm{~m}$, equation (12) implies that, if the surface reradiation is insignificant flame height is proportional to $x$ 0.76 for $Q_{\ell}<1.0, i . e . n \simeq 0.8$, and to $x_{p}^{0.8}$ for $Q_{\ell}^{*}>1.0,1 . e . n \simeq 2 / 3$. This relationship seems to be consistent with previous measurements of the average height of flame tips of wall fires; Orloff et a1 found $L^{\circ x} 0.782$ for $0.18<x<0.85 \mathrm{~m}$ of a vertical PMMA slab with side walls(4), and Kishitani et al obtained $L_{\mathrm{F}} \mathrm{x}^{0.774}$ for $0.05<\mathrm{x}<$ $0.50 \mathrm{~m}$ of a PMMA slab without side walls(17). The $\mathrm{F}$ asymptotes of this proportionality as $\mathrm{x}_{\mathrm{p}} \rightarrow \infty$ is $\mathrm{L}_{\mathrm{F}} \mathrm{x}_{\mathrm{x}}$, since $\mathrm{q}_{\mathrm{W}}^{\prime \prime}$ is approximately proportional to $\mathrm{x}^{0.5}$ for $x>1 \mathrm{~m}$. Using the following values of $\Delta \mathrm{H}_{\mathrm{c}}^{\mathrm{W}}, \Delta \mathrm{H}_{\mathrm{G}}$, qu and $\mathrm{q}_{\mathrm{Wr}}^{\mathrm{H}}$ for PMMA, $\Delta H_{c} / \Delta H_{G} \simeq 13, \dot{q}_{r r}^{n} \simeq 1 W / \mathrm{cm}^{2}, \dot{q}_{W}^{n} \simeq 3 x^{j} W / \mathrm{cm}^{2}(j \approx 0.2$ for $x \leqslant 1 \mathrm{~m}, j: 0.5$ for $x>1 \mathrm{~m})$

the flame height can be calculated from equation (12) as shown in Figure 8; the calculated values of $Q_{\ell}$ for $L_{p}<\operatorname{lm}$ were in the range of $0.17 \sim 0.21$, and this implies that a solid flame wbuld never cover the preheated region above a pyrolysis front for $L<1 \mathrm{~m}$. Therefore, the incident wall heat flux is never constant, although it $i \mathrm{p}$ assumed to be constant under the height of flame in some previous analysis (e.g.8). The higher flame height of orloff et al than Kishitani et al's is probably due to the presence of side walls. The calculation resulted in flame heights somewhat close to Kishitani et al's. 


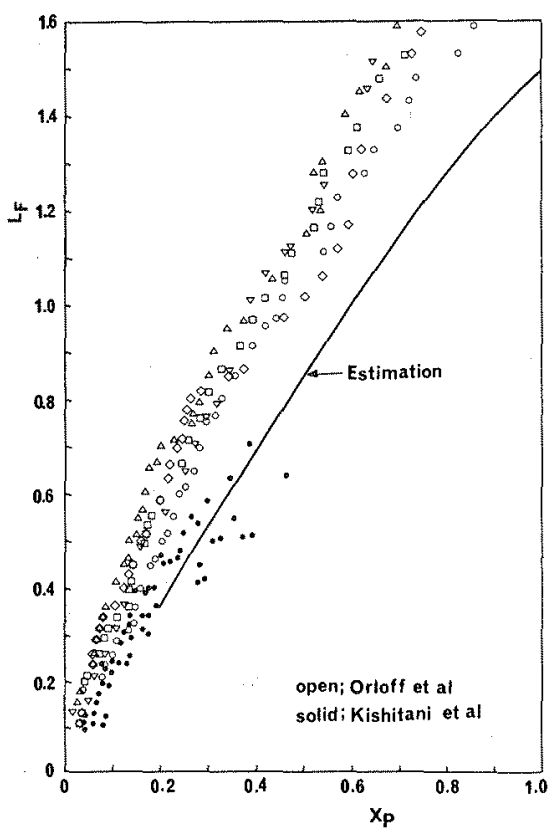

FIGURE 6. Experimental and calculated flame heights.

\section{Flame Spread Velocity}

Since the preheated region above a pyrolysis front is expected not to be covered with a solid flame for $\mathrm{L}<\mathrm{Im}$ of a PMMA vertical slab, flame spread velocity, formulated as equation (4) or (6), can be calculated by using only equations (10) and (11). Figure 7 compares the flame spread velocity estimated from the material properties for a semi-infinite thick wall with the result of experimental work by orloff et al and by Saito et al(18); this comparison demonstrates that the estimation tends to provide slightly larger velocity than the experiment. This seems to be reasonable, because a steady state flame spread velocity should give the upper limit of $v_{p}$ for growing wall flames.

\section{CONCLUSIONS}

Approximate relationships between the main wall flame properties and the thermometric fuel properties are derived from experiments using porous line burners against walls. The following conclusions can be drawn.

1) The flame height $*^{\text {against a }}$ wall is proportional to $Q_{\ell}^{*} \mathrm{D}$, where $\mathrm{n}$ is approximately 0.8 for $Q_{l}^{*}<1$ and $2 / 3$ for $Q_{l}^{*}>1$.

2) The incident heat flux to the wall surface is represented approximately as a function of $x / Q_{0}^{*} / 3$.

3) Estimation of wall flame height and flame spreading velocity from thermometric material properties using the heat transfer correlations obtained through the present experiment was found to be consistent with previous experimental work. 


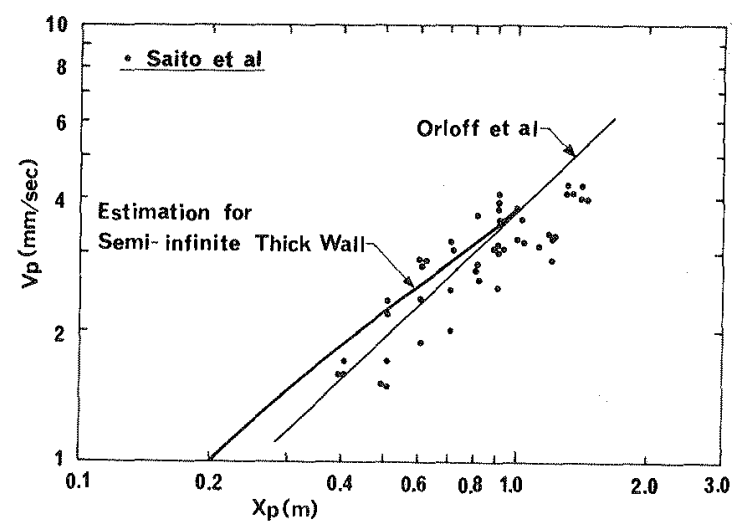

FIGURE 7. Experimental and calculated flame spread velocity.

\section{ACKNOWLEDGEMENTS}

The experiment introduced in this paper was conducted at the Center for Fire Research, NBS, Gaithersburg. The author wotld like to thank Dr.J.G.Quintiere and Mr.K.D. Steckler of NBS for the arrangement of the experiment. The author is also indepted to Mr.W.J.Rinkinen, Ms.M.Harkleroad and Mr.D. Wagger for the assistance in the experiment. Discussions of Dr.J.G.Quintiere and Dr.A.Robertson of NBS, and Dr.K.Saito of Princeton University are gratefu11y appreciated.

\section{REFERENCES}

1. de Ris,J.: Spread of a laminar diffusion flame. Twelfth Symposium (International) on Combustion,pp.241, 1968.

2. Fernandez-Pello,A.C, : A theoretical model for the upward laminar spread of flames over vertical surfaces. Combustion and Flame, 35, pp.135, 1978.

3. Annamalai,K., and Sibulkin,M.: Flame spread over combustible surfaces for laminar flow systems, Part I. Combustion Science and Technology, 19, pp.167, 1979.

4. Orloff,L., de Ris,J., and Markstein,G.H.: Upward turbulent fire spread and burning of fuel surface. Fifteenth symposium(International) on Combustion, pp. $183,1974$.

5. Orloff,L., Modak,A.T., and Alpert,R.L.: Burning of 1arge-scale vertical surfaces. Sixteenth Symposium on Combustion, pp.1345, 1976.

6. Fernandez-Pello,A.C., and Hirano,T.: Controlling mechanism of flame spread. Combustion Science and Technology, 32, pp.1, 1983.

7. Sibulkin,M., and Kim,J.: The dependence of flame propagation on surface heat transfer II, Upward burning. Combustion Science and Technology, 17, pp.39, 1977.

8. Quintiere,J.G., and Fernandez-Pe11o,A.C.: A simplified model of radiating turbulent upward flame spread over the surface of a charring combustible. Eastern Section Meeting, Combustion Institute, 1982.

9. Liburdy,J.A., and Faeth,G.M.: Fire induced plume along a vertical wa11, Part I. NBS Grant 5-9020, 1977.

10. Thomas,P.H., Webster,C.T., and Raftery,M,M.: Some experiments on buoyant diffusion flames. Combustion and Flame, 5, pp.359, 1961.

11. Steckler,K.D.: Fire induced flows through room opening-Flow coefficients. 
Technical Research Report, Armstrong World Industries, 1981.

12. Zukoski,E.E., Kubota,T., and Cetegen,B.: Entrainment in fire plumes. Fire Safety Journal, 3, pp.107, 1980/81.

13. Delichatsios,M.A.: Modeling of aircraft cabin fires. Technical Report, Factory Mutual Research Corp., 1984.

14. Kulkarni,A.K.: Pxivate communication. 1984.

15. Ahmad,T., and Faeth,G.M.: Fire induced plumes along a vertical wall, Part III. NBS Grant 5-9020, 1978.

16. Hasemi,Y.: Experimental wall flame heat transfer correlations for the analysis of upward flame spread. Fire Science and Technology, 4, 1984.

17. Kishitani,K., Sugawara,S., and Hamada,K.: Upward flame spread of building materials. "Saigai no Kenkyu", 15, pp.133, 1984( in Japanese).

18. Saito,K.: Private communication. 1985 (to be presented at the First International Symposium on Fire Safety Science, NBS)

\section{TERMINOLOGY}

$\mathrm{C}_{\mathrm{p}}$ : specific heat of air

$\mathrm{D}^{\mathrm{P}}$ : characteristic fuel size

$I_{F}$ : flame height

IF : pyrolysis length

$Q^{p} \quad$ : heat release rate

$Q^{*}$ : dimensionless heat release rate $\left(\ell / \rho_{\infty} C_{p} T_{0} \sqrt{g D}\right)$

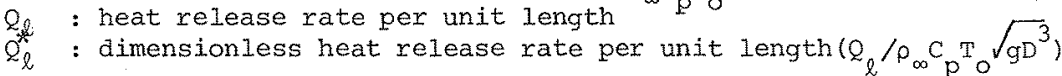

$Q_{x}$ : local heat flux $\left(\int_{0}^{\infty} \rho c_{p} u \theta d y\right)$

$T_{\text {ig }}$ : ignition temperature

$\mathrm{T}_{\mathrm{W}}^{\mathrm{ig}}$ : wall temperature

$\mathrm{V}^{W}$ : flame spread velocity

$c^{p}$ : specific heat of wall material

d : wall thickness

g : gravitational acceleration

$h_{i}$ : heat transfer coefficient

$k^{i}$ : thermal conductivity

$\dot{m}^{\prime \prime}$ : fuel vaporization rate

$q^{\mathrm{Y}}$ : convective heat flux to wall surface

$\dot{q}^{\prime \prime}$ : surface reradiation

grt : incident heat flux to wall surface

$t, \tau:$ time

u : upward velocity

$x$ : height from the bottom of fuel

$x_{p}$ : location of pyrolysis front

$y^{p}$ : horizontal coordinate normal to wall surface

$\Delta \mathrm{H}_{\mathrm{C}}$ : heat of combustion

$\Delta \mathrm{H}^{\mathrm{C}}$ : gasification heat

$\phi(E)$ : impulse response of $T_{W}$ to $\dot{q}_{W}$

: density

: excess temperature

: height from pyrolysis front

Suffix

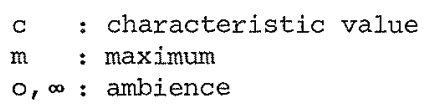

